\title{
A Fast, Low-Cost, and Environmental Friendly Micro-Flow-Batch Analyzer for Photometric Determination of Sulfites in Beverages
}

\author{
Márcio R. S. Tavares, ${ }^{a}$ Stéfani I. E. Andrade, ${ }^{\circ b}$ Marcelo B. Lima, ${ }^{c}$ Inakã S. Barreto, ${ }^{d}$ \\ Mário C.U. de Araújo ${ }^{\circledR} * b$ and Luciano F. Almeida ${ }^{b}$ \\ ${ }^{a}$ Instituto Federal de Educação, Ciência e Tecnologia do Sertão Pernambucano, \\ Campus Petrolina Zona Rural, 56300-000 Petrolina-PE, Brazil \\ ${ }^{b}$ Departamento de Química, Universidade Federal da Paraíba, 58051-970 João Pessoa-PB, Brazil \\ ${ }^{c}$ Universidade Federal Rural de Pernambuco, Unidade Acadêmica de Serra Talhada, \\ 56909-535 Serra Talhada-PE, Brazil \\ ${ }^{d}$ Instituto Federal de Educação, Ciência e Tecnologia da Paraíba, Campus Monteiro, \\ 58500-000 Monteiro-PB, Brazil
}

\begin{abstract}
An automated microsystem for sulfite determination in beverages was developed. It presents higher sampling throughput, lower chemical consumption and less waste generation than previous flow methods, while using the same $p$-rosaniline-formaldehyde-sulfite reaction. The sampling rate, limit of detection (LOD), and relative standard deviation (RSD) were estimated at $130 \mathrm{~h}^{-1}$, $80.0 \mu \mathrm{g} \mathrm{L} \mathrm{L}^{-1}$, and $<1.3 \%(\mathrm{n}=5)$, respectively. Recoveries ranged from 96.8 to $102.6 \%$.
\end{abstract}

Keywords: micro-flow-batch analyzer, sulfite, $p$-rosaniline-formaldehyde-sulfite reaction, beverage analysis

\section{Introduction}

To prevent undesirable oxidation processes, bacterial growth, and enzymatic reactions during production and storage, sulfur-based substances (such as: sulfur dioxide, metabisulfite, bisulfite, and sulfite) are widely used as food and beverage additives. ${ }^{1-4}$ However, if consumed above the permissible limits, they often represent real danger to humans through promotion of allergic and/or anaphylactic reactions, nasal congestion, coughing, breathing difficulties, asthma, headaches, abdominal pain, diarrhea, fatigue and irritation, itching, hives and other skin rashes. ${ }^{5-8}$ Quantification of sulfite in beverages and food is necessary to determine the amounts of sulfite to be added during production and storage, and to monitor the maximum allowed levels established by legislation in various countries. According to the Food and Agriculture Organization and the World Health Organization (FAO/ WHO) of the United Nations, ${ }^{9}$ the acceptable daily intake (ADI) of sulfite (expressed as $\mathrm{SO}_{2}$ ) is $0.7 \mathrm{mg} \mathrm{kg}^{-1}$ body weight.

*e-mail: laqa@quimica.ufpb.br
The Association of Official Analytical Chemists (AOAC) method $^{10}$ for determination of sulfite in foods and beverages involves distillation and titration; procedures which are slow, laborious, expensive, and inappropriate for detecting low sulfite concentrations. To overcome these drawbacks, automated flow methods have been developed. ${ }^{11-20}$

In the last two decades, flow-batch analysis (FBA) systems have gained great prominence. This is because such systems combine the useful and advantages of flow systems with well-established classical batch mode approaches. ${ }^{21}$ To reduce manufacturing costs, consumption of reagents and samples, and waste generation during traditional flow-batch (FB) system analyses, Monte-Filho et al. ${ }^{22}$ proposed the micro-flow-batch analyzer $(\mu \mathrm{FBA})$. The microsystem was built using photo-curable urethane-acrylate resin and ultraviolet lithography technique. It was initially employed with success for photometric determination of $\mathrm{Fe}^{\mathrm{II}}$ in supplemental oral iron solutions. Similar miniaturized systems were then successfully developed for photometric determinations of phosphorus in biodiesel, ${ }^{23}$ and iodate in table salt. ${ }^{24}$

The microsystem was later modified by employing a webcam as its detection system, introducing a digital 
image-based micro-flow-batch analyzer (DIB- $\mu$ FBA); a new strategy for implementing quantitative chemical analysis. DIB- $\mu$ FBA systems were then successfully applied to photometric determination of total tannins in teas..$^{25}$

In this paper, the $\mu \mathrm{FBA}$ micro-fabrication technology described in previous studies ${ }^{22-25}$ is resumed in order to develop an automated microsystem for photometric determination of total sulfite in wines, whiskies, vodkas and beers; all using the same selective and sensitive $p$-rosaniline-formaldehyde-sulfite reaction. The proposed microsystem was designed in order to maintain already highlighted features: high sampling throughput, low sample and reagent consumption, and little waste generation, as compared to other flow-based analyzers. ${ }^{11-14}$

\section{Experimental}

Working solutions, reagents, and samples

All reagents were of analytical grade, and freshly distilled and deionized water $(>18 \mathrm{M} \Omega \mathrm{cm}$ ) was always used.

Sulfite stock solution $\left(2.5 \mathrm{~g} \mathrm{~L}^{-1}\right)$ was prepared by dissolving $250 \mathrm{mg}$ of anhydrous sodium sulfite $\left(\mathrm{Na}_{2} \mathrm{SO}_{3}\right.$, J.T. Baker, USA) in $100 \mathrm{~mL}$ of water, and standardizing by iodometric titration. This stock solution was kept in a sealed bottle in a refrigerator at $4{ }^{\circ} \mathrm{C}$ when not in use. Fresh working standard solutions $\left(1.0-10.0 \mathrm{mg} \mathrm{L}^{-1}\right)$ were prepared using appropriate dilutions of the stock sulfite solution in water.

A solution of $p$-rosaniline hydrochloride $\left(0.34 \mathrm{~g} \mathrm{~L}^{-1}\right)$ was prepared by dissolving $40 \mathrm{mg}$ of this reagent $\left(\mathrm{C}_{19} \mathrm{H}_{17} \mathrm{~N}_{3} \mathrm{HCl}\right.$, Sigma-Aldrich, USA $)$ in $40 \mathrm{~mL}$ of water plus $6 \mathrm{~mL}$ of concentrated $\mathrm{HCl}(37 \% \mathrm{~m} / \mathrm{m}$, Vetec, Brazil), and then completing to $100 \mathrm{~mL}$ with water in a volumetric flask. To prepare the formaldehyde solution $(0.2 \% \mathrm{v} / \mathrm{v})$, a $0.5 \mathrm{~mL}$ volume of formaldehyde $(36.5-38 \% \mathrm{~m} / \mathrm{v}$, SigmaAldrich, USA) was also diluted with water to $100 \mathrm{~mL}$ in a volumetric flask.

Beverage samples (wines, whiskies, vodkas and beers) from several manufacturers were purchased from local retail suppliers in João Pessoa, Paraíba, Brazil. Before analyses using the proposed automated method, the beverages were diluted 10 -fold with water.

\section{$\mu$ FBA fabrication}

The $\mu$ FBA was fabricated using similar microfabrication technology, apparatus (micro-pumps, motor drive), tubes for fluids transport, a USB interface and software as described in a previous study. ${ }^{24}$ The differences were that a yellow-green light emitting diode (LED, $\lambda_{\max }=560 \mathrm{~nm}$ ) was employed as the radiation source, and a $48 \mu \mathrm{L}$ volume with an optical path of about $5 \mathrm{~mm}$ was used for each determination of sulfite in beverages. A diagram of the fabricated $\mu \mathrm{FBA}$ is presented in Figure 1.

The microsystem was mounted onto a suitable support in a black (darkroom) box $(10.0 \times 8.0 \times 4.0 \mathrm{~cm})$, to allow portability and isolate the microsystem from the effects of spurious environmental radiation while in operation. The solenoid micro-pumps were actuated at $2.5 \mathrm{~Hz}$, and the fluids were added with nominal values of $8 \mu \mathrm{L}\left(\mu \mathrm{P}_{1}-\mu \mathrm{P}_{4}\right)$ and $20 \mu \mathrm{L}$ $\left(\mu \mathrm{P}_{5}\right)$ per pulse (TFS, model MLP-200TF, MA, USA).

The proposed $\mu$ FBA method uses the same $p$-rosanilineformaldehyde-sulfite reaction seen in previous papers, ${ }^{11-14}$ and known for more than 50 years. ${ }^{26}$ Sulfite reacts with

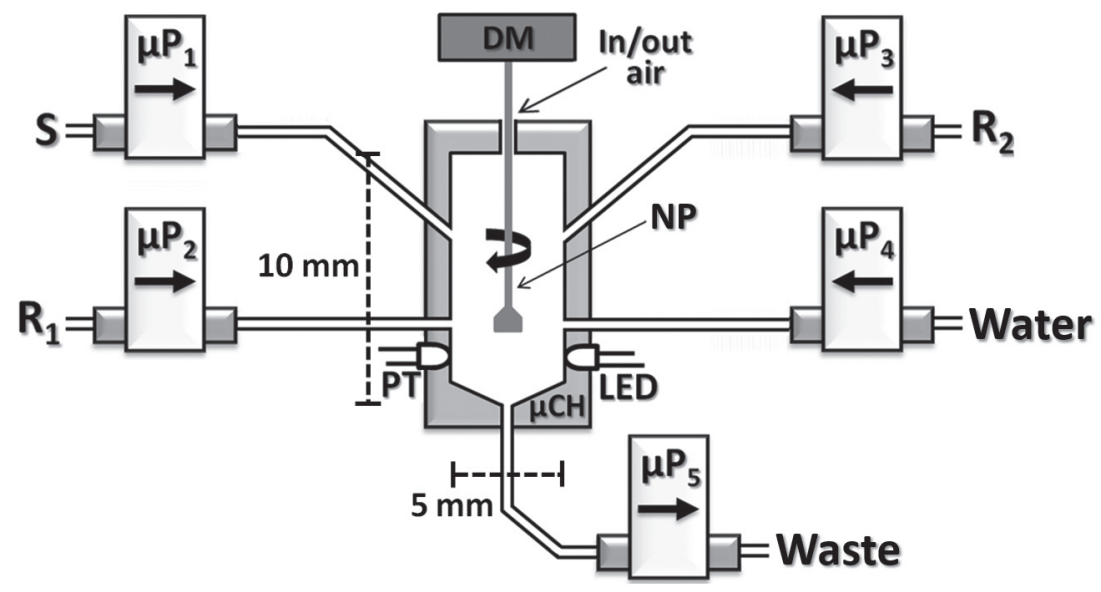

Figure 1. Micro-flow-batch analyzer $(\mu \mathrm{FBA})$ diagram. S: sample or working standard solutions; $\mathrm{R}_{1}$ : formaldehyde solution $(0.2 \% \mathrm{v} / \mathrm{v}) ; \mathrm{R}_{2}: p$-rosaniline solution (0.34 $\left.\mathrm{g} \mathrm{L}^{-1}\right) ; \mu \mathrm{CH}$ : micro-chamber $(100 \mu \mathrm{L}) ; \mu \mathrm{P}_{1}-\mu \mathrm{P}_{5}$ : solenoid metering micro-pumps (TFS, model MLP-200TF, MA, USA); DM: CD/DVD-ROM motor drive (model MDN3GT3CPAC, 2000 rpm, 5 V dc, China); NP: nylon paddle; LED: light emitting diode (Broadcom, model: HLMP-K640, $\lambda_{\max }=560 \mathrm{~nm}, \mathrm{USA}$ ); PT: phototransistor (Everlight, model: PT333-3C, Taiwan); In/out air: when solutions are introduced or removed from the $\mu \mathrm{CH}$, the inner air escapes by this air passage. 
formaldehyde and $p$-rosaniline (acidified with hydrochloric acid) to form a highly conjugated alkyl amino sulfonic acid, which presents an intense purple coloration and maximum absorption at $560 \mathrm{~nm} .{ }^{11,27}$ The $\mu$ FBA uses an integrated detection system, which employs a high intensity green LED with a maximum wavelength of $565 \mathrm{~nm}$ as its radiation source, a phototransistor as its detector, and a very simple electronic circuit described in detail elsewhere. ${ }^{28}$ The resulting measurements are converted to analytical responses (A) using equation 1 with software developed in the LabVIEW $^{\circledR}$ environment for the $\mu$ FBA's control and data acquisition.

$A=-\log \left[\frac{I_{S}-I_{\text {off }}}{I_{B}-I_{\text {off }}}\right]$

where $I_{B}, I_{S}$, and $I_{\text {off }}$ are the radiation intensities respectively related to the blank, sample or working standard solutions, and when the LED is switched off.

\section{Analytical procedure}

Before starting the procedure, the working solutions of each channel ( $S, R_{1}, R_{2}$ and water) were pumped towards the micro-chamber $(\mu \mathrm{CH})$ in order to fill the channels between the solution flasks and the $\mu \mathrm{CH}$ (Figure 1). This channel filling step was performed by switching on $\mu \mathrm{P}_{1}-\mu \mathrm{P}_{4}$ simultaneously (for 15 pulses). Then, the content inside the $\mu \mathrm{CH}$ was emptied by switching on $\mu \mathrm{P}_{5}$ (5 pulses) ( $\mu \mathrm{CH}$ emptying step) and the $\mu \mathrm{CH}$ cleaning step was then performed in triplicate. In the $\mu \mathrm{CH}$ cleaning step, $64 \mu \mathrm{L}$ of water was sent to the $\mu \mathrm{CH}$ by switching on $\mu \mathrm{P}_{4}$ (8 pulses), and the drive motor (DM) coupled to the nylon paddle (NP) was activated (DM/NP activation) for $2 \mathrm{~s}$ of agitation; then the $\mu \mathrm{CH}$ was emptied by switching on $\mu \mathrm{P}_{5}$ (5 pulses). Note that channel filling, cleaning and emptying steps were always carried out when the sample or a working standard solution was changed.
For the analytical procedure, each step involved, i.e., switching on/off of the solenoid micro-pumps and $\mathrm{DM} / \mathrm{NP}$ are presented in Table 1. Initially, $16 \mu \mathrm{L}$ each of $\mathrm{R}_{1}$ (formaldehyde), $\mathrm{R}_{2}$ ( $p$-rosaniline) and of sample or working standard solution were sent to the $\mu \mathrm{CH}$ by switching on (2 pulses) of $\mu \mathrm{P}_{1}, \mu \mathrm{P}_{2}$ and $\mu \mathrm{P}_{3}$ simultaneously. The DM/NP was then immediately activated for the homogenization/reaction. In sequence, absorbance was measured and the $\mu \mathrm{CH}$ was emptied by switching on $\mu \mathrm{P}_{5}$ (5 pulses). Finally, the $\mu \mathrm{CH}$ cleaning and emptying steps were carried out.

The procedures for blank and working standard solution measurements were similar to that described for the sample analysis. The difference is that water or working standard solution was used instead of the sample.

\section{Reference method}

As reference method, the Association of Official Analytical Chemists (AOAC) method ${ }^{10}$ for determination of sulfite in foods and beverages was used. Briefly, the sample is acidified and the formed $\mathrm{SO}_{2}$ is drawn out by a nitrogen stream to react with hydrogen peroxide and to produce sulfuric acid that is titrated with an $\mathrm{NaOH}$ standard solution.

\section{Results and Discussion}

\section{$\mu$ FBA features}

The reagent concentrations (optimized) used in the proposed $\mu$ FBA method were similar to those employed in previous papers. ${ }^{11,27}$ The volumes chosen for the reagents, samples or working standard solutions were evaluated in order to improve the reproducibility of the analytical signal, increase the sampling throughput, and to decrease the consumption of samples and reagents while minimizing generation of waste. Optimization studies were performed inside the proposed $\mu \mathrm{FBA}$

Table 1. Steps of the analytical procedure

\begin{tabular}{|c|c|c|c|c|c|c|c|c|c|}
\hline Step & Description & $\mu \mathrm{P}_{1}$ & $\mu \mathrm{P}_{2}$ & $\mu \mathrm{P}_{3}$ & $\mu \mathrm{P}_{4}$ & $\mu \mathrm{P}_{5}$ & Pulse & time $/ \mathrm{s}$ & Volume / $\mu \mathrm{L}$ \\
\hline 1 & addition of $\mathrm{R}_{1}, \mathrm{R}_{2}$ and sample & on & on & on & off & off & 2 & 0.8 & $16^{\mathrm{a}}$ \\
\hline 2 & DM/NP activation for homogenization/reaction & off & off & off & off & off & - & 2.0 & - \\
\hline 3 & absorbance measurement & off & off & off & off & off & - & 1.0 & - \\
\hline 4 & emptying step of the $\mu \mathrm{CH}$ & off & off & off & off & on & 5 & 2.0 & - \\
\hline $5^{\mathrm{b}}$ & addition of water & off & off & off & on & off & 8 & 3.2 & 64 \\
\hline $6^{\mathrm{b}}$ & $\mathrm{DM} / \mathrm{NP}$ activation for agitation & off & off & off & off & off & - & 2.0 & - \\
\hline $7^{\mathrm{b}}$ & emptying step of the $\mu \mathrm{CH}$ & off & off & off & off & on & 5 & 2.0 & - \\
\hline
\end{tabular}

${ }^{a} 16 \mu \mathrm{L}$ of each $\mathrm{R}_{1}, \mathrm{R}_{2}$ and sample (total $=48 \mu \mathrm{L}$ ); ${ }^{\text {bsteps }} 5$ to 7 are carried out three times. $\mu \mathrm{P}_{1}-\mu \mathrm{P}_{5}$ : solenoid metering micro-pumps; $\mathrm{R}_{1}$ : formaldehyde solution; $\mathrm{R}_{2}$ : p-rosaniline solution; DM: CD/DVD-ROM motor drive; NP: nylon paddle; $\mu \mathrm{CH}$ : micro-chamber. 
(automatically), considering the maximum inner volume of the micro-chamber $(100 \mu \mathrm{L})$. The evaluated volume range was $8-32 \mu \mathrm{L}$, and the selected value for analysis was $16 \mu \mathrm{L}$ of sample and of each reagent. Differing sample dilutions may be used by addition of water in-line, and simply changing the $\mu \mathrm{FBA}$ operational parameters in the control software as needed.

\section{Effect of interferences and recovery study}

Effects of potentially interfering species on the $p$-rosaniline-formaldehyde-sulfite reaction have been studied in previous papers. ${ }^{11-14,26,27}$ It was found that cations, anions, organic acids, sugars, ethanol, and other species that might co-exist in the analyzed samples do not appreciably affect the analytical signal under the chemical analysis conditions of those works. However, effect of potentially interfering species $\left(\mathrm{Cu}^{2+}, \mathrm{Mn}^{2+}, \mathrm{Mg}^{2+}, \mathrm{Cr}^{3+}, \mathrm{Fe}^{3+}\right.$, potassium sodium tartrate, sodium citrate and ascorbic acid) were also tested under the chemical analysis conditions of this work. An analytical signal difference of $\pm 5 \%$ between $1.0 \mathrm{mg} \mathrm{L}^{-1}$ of sulfite with and without interfering species was taken as the criterion for identifying interference. Tolerable concentration ratios were: $\mathrm{Cu}^{2+}=3, \mathrm{Mn}^{2+}=15, \mathrm{Mg}^{2+}=100$, $\mathrm{Cr}^{3+}=8, \mathrm{Fe}^{3+}=5$, potassium sodium tartrate $=500$, sodium citrate $=250$, and ascorbic acid $=300$.

No significant effect in the analytical signal of the sample matrix or of interfering species were observed in the recovery testes performed by adding $1.00 \mathrm{~mL}$ of standardized sulfite solutions $\left(0.50,1.00\right.$, and $\left.2.00 \mathrm{mg} \mathrm{L}^{-1}\right)$ to $1.00 \mathrm{~mL}$ of samples (whiskies, vodkas, beers, red and white wines). As can be seen in Table 2, the recovery values ranged from 96.8 to $102.6 \%$.

Table 2. Sulfite recoveries in beverages $(n=3)$

\begin{tabular}{lcccc}
\hline & & Initial & \multicolumn{3}{c}{ Recovery / \% } \\
\cline { 3 - 5 } Sample & $\begin{array}{c}\text { concentration } \\
\left(\mathrm{mg} \mathrm{L}^{-1}\right)\end{array}$ & $0.50 \mathrm{mg} \mathrm{L}^{-1}$ & $1.00 \mathrm{mg} \mathrm{L}^{-1}$ & $2.00 \mathrm{mg} \mathrm{L}^{-1}$ \\
\hline \multirow{2}{*}{ White wine } & 5.64 & $98.9 \pm 2.3$ & $99.3 \pm 2.2$ & $102.3 \pm 2.5$ \\
& 4.45 & $99.5 \pm 2.5$ & $101.6 \pm 2.4$ & $97.8 \pm 2.3$ \\
Red wine & 7.55 & $97.5 \pm 2.3$ & $102.5 \pm 1.9$ & $101.6 \pm 2.1$ \\
& 4.80 & $99.8 \pm 2.4$ & $97.9 \pm 2.2$ & $102.4 \pm 2.3$ \\
Whisky & 2.56 & $97.6 \pm 2.0$ & $96.8 \pm 2.1$ & $102.6 \pm 2.4$ \\
& 2.03 & $101.8 \pm 1.9$ & $99.3 \pm 2.3$ & $101.5 \pm 2.1$ \\
Beer & 3.65 & $99.1 \pm 2.2$ & $98.5 \pm 2.3$ & $100.8 \pm 2.5$ \\
& 1.69 & $102.2 \pm 2.4$ & $98.9 \pm 2.4$ & $102.4 \pm 2.1$ \\
\hline
\end{tabular}

Analytical features, application, and critical comparison

A satisfactory analytical curve for the sulfite determination using the proposed method was estimated using linear regression, yielding: $\mathrm{A}=0.1168+0.0271 \mathrm{C}$, where $\mathrm{A}$ was the absorbance and $\mathrm{C}$ was the concentration of sulfite in the range from 1.0 to $10.0 \mathrm{mg} \mathrm{L}^{-1}$, and $\mathrm{r}^{2}$ (linear correlation coefficient $)=0.9991$. To evaluate the fit for a linear model of the analytical curve, three authentic replicate measurements were made at each concentration level and an analysis of variance (ANOVA) was carried out according to recommendations described elsewhere. ${ }^{29}$ No lack of fit was evidenced for the model and heteroscedasticity was maintained. The linear regression was significant at the $95 \%$ confidence level. The LOD (limit of detection) $=80.0 \mu \mathrm{g} \mathrm{\textrm {L } ^ { - 1 }}$ and LOQ (limit of quantification $)=280 \mu \mathrm{g} \mathrm{L}^{-1}$ were estimated based on the criteria established by IUPAC. ${ }^{30}$

Results obtained using both the proposed $\mu \mathrm{FBA}$ and the reference methods are presented in Table 3. No statistically significant differences were observed between the results when applying the paired $t$-test at a $95 \%$ confidence level. The proposed method also presented satisfactory repeatability with a relative standard deviation (RSD) of less than $1.24 \%(n=5)$.

The possibility of varying dilution in a simple way is an interesting feature of the flow-batch systems. Considering the maximum internal volume of the micro-chamber $(100 \mu \mathrm{L})$ and the minimum volume of sample that can be added to this micro-chamber ( $8 \mu \mathrm{L}$, which corresponds to the application of 1 pulse of current to the micro-pump), only a 12.5 -fold maximum dilution can be performed in-line. However, sulfite concentrations in the samples were expected to range from 30 to $300 \mathrm{mg} \mathrm{L}^{-1}$ and a 12.5-fold dilution is not sufficient for the responses of the analyzed sample to fall within the linear work range (1.0 to $10.0 \mathrm{mg} \mathrm{L}^{-1}$ ). Therefore, a prior 10 -fold dilution of the samples was required.

Table 4 presents certain analytical features between the proposed $\mu$ FBA and other flow methods, ${ }^{11-14}$ which for sulfite determinations also use the $p$-rosanilineformaldehyde-sulfite reaction.

As can be seen, the proposed $\mu$ FBA method presents better sampling rate and precision, besides lower sample and reagent consumption, and less waste generation than previous FBA ${ }^{11}$ and flow methods. ${ }^{12-14}$ The proposed method also employs an integrated detection system, which does not use a carrier fluid as in previous methods, ${ }^{12-14}$ this avoids associated dispersion problems such as loss of sensitivity and limit of detection.

\section{Conclusions}

A simple, robust, low-cost and portable $\mu \mathrm{FBA}$ was built and used to develop an automated method for sulfite 
Table 3. Mean, values of standard (SD) and relative standard deviations (RSD) for five replicate determinations of sulfite in beverages using the proposed $\mu \mathrm{FBA}$ and the reference methods

\begin{tabular}{|c|c|c|c|c|}
\hline \multirow{2}{*}{ Sample } & \multicolumn{2}{|l|}{ Reference } & \multicolumn{2}{|l|}{$\mu \mathrm{FBA}$} \\
\hline & Concentration $\pm \mathrm{SD} /\left(\mathrm{mg} \mathrm{L}^{-1}\right)$ & $\mathrm{RSD} / \%$ & Concentration $\pm \mathrm{SD} /\left(\mathrm{mg} \mathrm{L}^{-1}\right)$ & $\mathrm{RSD} / \%$ \\
\hline \multirow{5}{*}{ White wine } & $5.23 \pm 0.04$ & 0.74 & $5.09 \pm 0.03$ & 0.60 \\
\hline & $4.65 \pm 0.05$ & 1.07 & $4.72 \pm 0.04$ & 0.75 \\
\hline & $4.89 \pm 0.04$ & 0.72 & $4.85 \pm 0.03$ & 0.52 \\
\hline & $5.71 \pm 0.05$ & 0.80 & $5.64 \pm 0.03$ & 0.56 \\
\hline & $4.38 \pm 0.04$ & 0.86 & $4.45 \pm 0.04$ & 0.92 \\
\hline \multirow{5}{*}{ Red wine } & $6.33 \pm 0.04$ & 0.65 & $6.39 \pm 0.04$ & 0.62 \\
\hline & $7.69 \pm 0.06$ & 0.76 & $7.55 \pm 0.06$ & 0.77 \\
\hline & $5.98 \pm 0.06$ & 1.02 & $6.05 \pm 0.05$ & 0.81 \\
\hline & $5.24 \pm 0.05$ & 1.04 & $5.30 \pm 0.04$ & 0.66 \\
\hline & $4.76 \pm 0.04$ & 0.84 & $4.80 \pm 0.04$ & 0.80 \\
\hline \multirow{3}{*}{ Whisky } & $2.63 \pm 0.03$ & 0.96 & $2.56 \pm 0.02$ & 0.82 \\
\hline & $2.38 \pm 0.03$ & 1.24 & $2.34 \pm 0.01$ & 0.47 \\
\hline & $1.96 \pm 0.02$ & 0.99 & $2.03 \pm 0.01$ & 0.59 \\
\hline \multirow{3}{*}{ Vodka } & $2.45 \pm 0.02$ & 0.87 & $2.51 \pm 0.02$ & 0.62 \\
\hline & $3.88 \pm 0.03$ & 0.73 & $3.92 \pm 0.02$ & 0.56 \\
\hline & $3.65 \pm 0.03$ & 0.81 & $3.72 \pm 0.02$ & 0.51 \\
\hline \multirow{3}{*}{ Beer } & $1.75 \pm 0.02$ & 1.17 & $1.69 \pm 0.02$ & 0.89 \\
\hline & $3.67 \pm 0.03$ & 0.84 & $3.65 \pm 0.02$ & 0.68 \\
\hline & $2.81 \pm 0.02$ & 0.78 & $2.87 \pm 0.02$ & 0.66 \\
\hline
\end{tabular}

$\mu$ FBA: micro-flow-batch analyzer.

Table 4. Analytical features of the proposed and other flow methods for the sulfite determination in beverages using the same $p$-rosaniline-formaldehyde$\mathrm{SO}_{2}$ reaction

\begin{tabular}{|c|c|c|c|c|c|}
\hline Parameter & $\begin{array}{c}\mu \mathrm{FBA} \\
\text { (this work) }\end{array}$ & $\mathrm{FBA}^{11}$ & SIA $^{12}$ & FIA $^{13}$ & FIA $^{14}$ \\
\hline Limit of detection / $\left(\mu \mathrm{g} \mathrm{L}^{-1}\right)$ & 80.0 & 40.0 & 600 & 1.200 & - \\
\hline $\begin{array}{l}\text { Working concentration range / } \\
\left(\mathrm{mg} \mathrm{L}^{-1}\right)\end{array}$ & $1.0-10.0$ & $0.13-32.7$ & $25-250$ & $2.0-20$ & $1.0-16.0$ \\
\hline RSD / \% & $<1.3(\mathrm{n}=5)$ & $<3.1(\mathrm{n}=5)$ & $<2.3(\mathrm{n}=10)$ & $<3.0(\mathrm{n}=3)$ & $<4.0$ \\
\hline Sampling rate $/ \mathrm{h}^{-1}$ & 130 & 43 & 16 & 12 & 35 \\
\hline $\begin{array}{l}p \text {-Rosaniline consumption per } \\
\text { determination / } \mu \mathrm{g}\end{array}$ & 6 & 34 & 58 & 2500 & 267 \\
\hline $\begin{array}{l}\text { Formaldehyde consumption per } \\
\text { determination / } \mu \mathrm{g}\end{array}$ & 26 & 163 & 2339 & 8150 & 870 \\
\hline $\begin{array}{l}\text { Sample consumption per } \\
\text { determination / } \mu \mathrm{L}\end{array}$ & 16 & 1050 & 238 & 500 & 70 \\
\hline $\begin{array}{l}\text { Waste generation per } \\
\text { determination } / \mathrm{mL}\end{array}$ & 0.064 & 2.7 & 6.075 & 8.25 & 3.194 \\
\hline Detection strategy & $\begin{array}{c}\text { photometer (integrated } \\
\text { detection) }\end{array}$ & $\begin{array}{c}\text { webcam (integrated } \\
\text { detection) }\end{array}$ & spectrophotometer & spectrophotometer & spectrophotometer \\
\hline Carrier fluid & absent & absent & $\begin{array}{l}\text { hydrochloric acid } \\
\qquad\left(0.8 \mathrm{~mol} \mathrm{~L}^{-1}\right)\end{array}$ & $\begin{array}{l}\text { formaldehyde } \\
\left(1.0 \mathrm{~g} \mathrm{~L}^{-1}\right) / \\
\text { p-rosaniline } \\
\left(4.0 \mathrm{~g} \mathrm{~L}^{-1}\right)\end{array}$ & $\begin{array}{l}\text { formaldehyde } \\
\left(1.0 \mathrm{mg} \mathrm{L}^{-1}\right) / \\
\text {-rosaniline } \\
\left(4.0 \mathrm{~g} \mathrm{~L}^{-1}\right)\end{array}$ \\
\hline Sample & beverages & vinegar & wines & wines & wines \\
\hline
\end{tabular}

$\mu$ FBA: micro-flow-batch analyzer; SIA: sequential injection analysis; FIA: flow injection analysis; RSD: relative standard deviation. 
determination in red and white wines, whiskies, vodkas and beers. Compared to other flow methods ${ }^{11-14}$ that also use the $p$-rosaniline-formaldehyde-sulfite reaction, the proposed $\mu$ FBA method presents higher sample throughput, lower sample and reagent consumption, and less waste generation, contributing to the basic principles of green chemistry and the advancement of microanalysis. Further, the proposed $\mu$ FBA method does not present dispersion problems, such as sensitivity or detection limit losses when compared to the reported in previous works, ${ }^{12-14}$ since it employs an integrated detection system which does not use a carrier fluid as the flow-batch method. ${ }^{11}$ In addition, the detection and quantification limits, working concentration range, precision, and accuracy of the proposed $\mu \mathrm{FBA}$ method are compatible with the AOAC reference method, ${ }^{10}$ permitting its use for monitoring maximum sulfite levels in foods and beverages as established by FAO/WHO, ${ }^{9}$ and other legislation in various countries. Being faster and more environmentally friendly than the AOAC reference method, ${ }^{9}$ traditional photometry, ${ }^{27}$ and previous automatic flow methods, ${ }^{11-14}$ it may well be considered useful for routine laboratory analysis.

\section{Acknowledgments}

The authors would like to thank the Brazilian agencies (CNPq and CAPES) for research fellowships and scholarships.

\section{References}

1. Ruiz-Capillas, C.; Jiménez-Colmenero, F.; Food Chem. 2009, 112, 487.

2. Abdel-Latif, M. S.; Anal Lett. 1994, 27, 2601.

3. Li, Y.; Zhao, M.; Food Control 2006, 17, 975.

4. Machado, R. M. D.; Toledo, M. C. F.; Vicente, E.; Braz. J. Food Technol. 2006, 9, 265.

5. https://www.canada.ca/content/dam/hc-sc/documents/services/ food-nutrition/reports-publications/food-safety/2017-sulphitessulfites-eng.pdf, accessed in August 2018.

6. Bold, J.; Gastroenterol. Hepatol. Bed Bench 2012, 5, 3.

7. Kencebay, C.; Derin, N.; Ozsoy, O.; Kipmen-Korgun, D.; Tanriover, G.; Ozturk, N.; Basaranlar, G.; Yargicoglu-Akkiraz, P.; Sozen, B.; Agar, A.; Food Chem. Toxicol. 2013, 52, 129.

8. Costanigro, M.; Appleby, C.; Menke, S. D.; Food Qual. Prefer. 2014, 31, 81 .

9. http://www.inchem.org/documents/jecfa/jeceval/jec_2215.htm, accessed in August 2018.

10. Cunniff, P.; Association of Official Analytical Chemists (AOAC); Official Methods of Analysis of AOAC International, $16^{\text {th }}$ ed.; AOAC International: Arlington, USA, 1995, ch. 47, p. 27.
11. Almeida Jr., P. L.; Bonfim, T. H. F.; Cunha, F. A. S.; Lima, K. M. G.; Aquino, J. S.; Almeida, L. F.; Anal. Methods 2018, 10, 448.

12. Segundo, M. A.; Rangel, A. O. S. S.; Anal. Chim. Acta 2001, 427, 279.

13. Mataix, E.; de Castro, M. D. L.; Analyst 1998, 123, 1547.

14. Lazaro, F.; de Castro, M. D. L.; Valcárcel, M.; Anal. Chem. 1987, 59, 950 .

15. Alamo, L. S. T.; Tangkuaram, T.; Satienperakul, S.; Talanta 2010, 81, 1793.

16. Tzanavaras, P. D.; Thiakouli, E.; Themelis, D. G.; Talanta 2009, 77, 1614.

17. Paula, N. T. G.; Barbosa, E. M. O.; Silva, P. A. B.; Souza, G. C. S.; Nascimento, V. B.; Lavorante, A. F.; Food Chem. 2016, 203, 183.

18. Yin, L. Q.; Yuan, D. X.; Zhang, M.; Chin. Chem. Lett. 2010, 21, 1457.

19. Dong, Y.; Dayou, F.; Wenyuan, T.; Appl. Mech. Mater. 2013, 295, 950.

20. Chantipmanee, N.; Alahmad, W.; Sonsa-ard, T.; Uraisin, K.; Ratanawimarnwong, N.; Mantim, T.; Nacapricha, D.; Anal. Methods 2017, 9, 6092.

21. Diniz, P. H. G. D.; Almeida, L. F.; Harding, D. P.; Araújo, M. C. U.; Trends Anal. Chem. 2012, 35, 39.

22. Monte-Filho, S. S.; Lima, M. B.; Andrade, S. I. E.; Harding, D. P.; Fagundes, Y. N. M.; Santos, S. R. B.; Lemos, S. G.; Araújo, M. C. U.; Talanta 2011, 86, 208.

23. Lima, M. B.; Barreto, I. S.; Andrade, S. I. E.; Neta, M. S. S.; Almeida, L. F.; Araújo, M. C. U.; Talanta 2012, 98, 118.

24. Lima, M. B.; Barreto, I. S.; Andrade, S. I. E.; Almeida, L. F.; Araújo, M. C. U.; Talanta 2012, 100, 308.

25. Lima, M. B.; Andrade, S. I. E.; Barreto, I. S.; Almeida, L. F.; Araújo, M. C. U.; Microchem. J. 2013, 106, 238.

26. Pate, J. B.; Ammons, B. E.; Swanson, G. A.; Lodge, J. P.; Anal. Chem. 1965, 37, 942.

27. Singla, M. L.; Singh, M.; Walia, M. S.; Singla, S.; Mahapatra, P. K.; Food Chem. 2006, 97, 737.

28. Barreto, I. S.; Lima, M. B.; Andrade, S. I. E.; Araújo, M. C. U.; Almeida, L. F.; Anal. Methods 2013, 5, 1040.

29. Draper, N. R.; Smith, H.; Applied Regression Analysis, $3^{\text {rd }}$ ed.; Wiley: New York, USA, 1998.

30. McNaught, A. D.; Andrew, W.; IUPAC Compendium of Chemical Terminology, $2^{\text {nd }}$ ed.; Royal Society of Chemistry: Cambridge, UK, 1997.

Submitted: October 29, 2018 Published online: December 13, 2018 